\title{
One to One Technology and its Effect on Student Academic Achievement and Motivation
}

\author{
Jennifer L. Harris \\ Illinois State University, United States \\ Mohammed T. Al-Bataineh \\ Jordan University of Science and Technology, Jordan \\ Adel Al-Bataineh \\ Illinois State University, United States
}

\begin{abstract}
This research was a quantitative study using $4^{\text {th }}$ grade participants from a Title 1 elementary school in Central Illinois. This study set out to determine whether one to one technology (1:1 will be used hereafter) truly impacts and effects the academic achievement of students. This study's second goal was to determine whether 1:1 Technology also effects student motivation to learn. Data was gathered from students participating in this study through the Pearson enVision Math series with Topic Tests, Discovery Education Assessment results, and attendance records being used. The results show that 1:1 Technology could be a factor in student academic achievement and motivation to be at school. These findings are important due to the technological shift that schools are currently facing. With more technology exposure for students and more professional development for teachers to hone their newly acquired teaching methods, 1:1 Technology may be the catalyst needed for school districts to help their students achieve at higher levels.
\end{abstract}

Keywords: One to one technology; Technology implementation; Student motivation; Academic achievement.

\section{Introduction}

Since No Child Left Behind's inception, high stakes testing and accountability has beleaguered school districts across the nation. School officials and administrators have tried any and all sorts of remedies to promote student engagement and success in the classrooms, this includes implementing technology into curricula. According to the United States Department of Education (2002), the No Child Left Behind Act also sought to eliminate the digital divide and to have student technologically literate by the end of the eighth grade, regardless of race, socioeconomic status, geographic location, and disability. 
Furthermore, the State of Illinois adopted the Common Core State Standards in 2010, with them being fully implemented in the 2013-2014 school year. These standards have taken the ideals from No Child Left Behind (NCLB) one step further with children as young as Kindergarten aged being computer literate. For example, instead of writing extended response questions, students are expected to type and compose such responses. Current assessment initiatives require school district to use online testing. The new Partnership for Assessment of Readiness for College and Careers (PARCC), which replaces the ISAT Test in the state of Illinois, will be taken online which is a vast difference between old state assessments and new state assessments. These changes are requiring school districts to provide computers and technology to their students and faculty.

The school district participating in this study adopted an initiative for 1:1 Technology to be a part of classrooms in the last few years. This past school year, the school district was able to have select classrooms pilot 1:1 Technology. Teachers at the high school, junior high, and elementary levels were chosen by district administrators to have laptops as a resource and tool for instruction and learning in the classroom. The school district is working closely with local business for this 1:1 initiative to be district-wide in the near future. Due to the State of Illinois' continued budget concerns, this is not happening as quickly as it was projected to be. Teachers who are using 1:1 Technology are at an advantage over teachers who do not have this accessibility. 1:1 Technology allows teachers to better and more quickly differentiate, to administer enrichment, and to also dive deeper into topics of study, as the Common Core State Standards puts forth these requirements for students. 1:1 Technology can also motivate students and allow them to be engaged on a completely different level than they have ever before. This study examined whether 1:1 Technology does in fact increase student academic achievement and increase motivation in students to learn.

One of the main items that No Child Left Behind set out to accomplish was to diminish the digital divide between socioeconomic class and race of students. The school district participating in this study there are two elementary schools that are inundated with higher percentages of low-income students. The majority students do not have the same opportunities to be exposed or have the background or previous knowledge with computing skills and are more often than not, technologically illiterate. Two classrooms from the participating school district were chosen to pilot 1:1 Technology. The hope and goal of this pilot is to see if $1: 1$ Technology can improve student academic achievement in the classroom. This study then took that goal one step further by examining the effects of 1:1 technology on student motivation.

This study should be useful to legislators, school administrators, and educators as most of our schools are turning to technology to aid and assist in learning in the classrooms. 1:1 Technology is such an asset to any school or classroom. The use of technology allows teachers to truly differentiate and tailor instruction to meet the needs of their students. With the new Common Core State Standards being implemented and the new appraisal process being fully embraced by the state of Illinois, 1:1 Technology and being technologically literate is such an essential skill for educators, but more importantly, students. This study set out to show how technology can positively affect student academic achievement and motivation in the classroom. 


\section{Literature Review}

Technology is a recent marvel in our everyday life that has taken off. Technology allows the most difficult tasks to become seamlessly easy and more efficient. In education, technology has allowed the dissemination of knowledge to be dispersed instantly and it allows for quicker and more effective communication. Also, technology has allowed students to be engaged and learn in ways that they never have in a classroom setting before. According to Spears (2012) she cites Donovan, Hartley \& Strudler (2007) and describes the first 1:1 technology program that was used in a school setting. Spears (2012) states, "The first provider of 1:1 computer access for teachers and students was Apple Classrooms of Tomorrow (ACOT). The goal of ACOT was to promote change in the context of education"(p. 1). Spears continues in her study and describes Microsoft's 1:1 initiative through the Anytime Anywhere Learning (AAL) program. Spears (p. 1) cites the work of Donovan et al. (2007), "An increase in enthusiasm for teaching and learning with technology, an improvement in student writing skills, an increase of authentic and purposeful use of technology...are some of the benefits of 1:1 technology integration programs like the AAL program." These programs in the 1980's and 1990 's paved the way for presidents, legislators, administrators, and educators to become aware of how positively technology could impact the student and teacher in the classroom, alike.

\section{The Role of Educational Reform in Technology Development}

The role of technology in the world of education has been ever changing. Most recently, technology has been a new phenomenon to help motivate, differentiate, and allow students to achieve and excel in ways that they have never been able to before. According to Johnson (2003), the computer and technology, if used correctly, has the ability to "invoke dream in the minds of visionary educators who saw endless potential for altering traditional notions of teaching and learning" ( $p$. 2). Two past presidents saw the need for fundamental change in education to keep American students in competition with technology with other students from around the world. In 1994, President Bill Clinton signed The Goals 2000: Educate America Act (Goals 2000: Educate America Act, 1994). There were many parts of this bill that involved technology and education. Part C of The Goals 2000: Educate America Act, Leadership in Technology, (a) calls upon the Department of Education to create a national strategy to involve technology into all educational programs and the state and local school systems, (b) foster understanding of how technology can be used to improve teaching and learning, (c) show how technology can be used to create an equal opportunity for all students to be successful while meeting state education requirements, and (g) create high-quality professional education opportunities for educators with the ability to integrate technology into their instruction (Goals 2000: Educate America Act, 1994).

After President Bill Clinton signed this bill into action, President George W. Bush pushed one step further with education and technology while he passed the No Child Left Behind (NCLB) Act in 2001. This bill sought to close the achievement gap in education, while also creating accountability amongst schools and states, alike, and choice and flexibility so no child is left behind in education. (No Child Left Behind Act of 2001, 2002). The goal of Part D of the No Child Left Behind Act was to improve student academic achievement through the use of technology. The main points of Part $D$, Enhancing Education through Technology Act of 2001 include, (a) assistance to states for the 
implementation of technology into schools, elementary and secondary, to promote and encourage student academic achievement, (b) establish and develop technology initiatives in regards to access to technology, (c) assistance for acquisition of technology, which increases the amount of students who have accessibility to technology, (e) professional development initiatives for teachers and administrators, (h) supports for efforts to involve families in education and to help in communication (No Child Left Behind Act of 2001, 2002). The No Child Left Behind Act also sought to decrease the digital divide between students and to also use best practices while integrating technology with teacher training to establish research-based instructional methods.

Again in 2009, President Barack Obama signed the American Recovery and Reinvestment Act, which provided $\$ 4.35$ billion for the Race to the Top Fund for education innovation and reform (Race to the Top Program Executive Summary, 2009). Spears (2012) cites Duncan (2009), the United States Secretary of Education, refers to Race to the Top as "education reform's moon shot" in a commentary describing the largest unrestricted fund for education in the history of the country. Spears $(2012$, p. 3) states in her work that the emphasis of Priority 2 of Race to the Top (Race to the Top Executive Summary, 2009, p. 1) is the rigorous preparation of students in science, technology, engineering, and mathematics (STEM). In 2010 the President's Council of Advisors on Science and Technology issued a report to the president. This report indicated that there is the need for urgency of preparing American students with a strong foundation in science, technology, engineering, and mathematics in order for students to transfer this knowledge in their personal and professional lives, which will then also impact the American society. Spears $(2012$, p. 4) states that the Council acknowledges that ICT can be a driving force for education innovation through the improvement of instructional material quality, the development of high-quality assessments that indicate student learning, and the increased use of data to provide rich feedback to students, teachers, and schools (President's Council of Advisors on Science and Technology, 2010, p. 73).

\section{Educational Technology Challenges}

Although these past presidents were able to have legislation passed, there are still many difficulties with technology being introduced and immersed in schools (Brinkerhoff, 2006). Legislation being passed is not enough. There are so many students without accessibility, and the digital divide still exists in schools to this day. The financial constraints that the school districts and states are under make immersing technology even more difficult. The cost, infrastructure, and technology development in schools across the country is not the same. Most technology used in schools are computer labs that classes can schedule times for students use, or some schools have three to four desktop computers for classroom and teacher use in the classrooms. There are some school districts, however, that are able to provide 1:1 Technology experiences for students, but not all students have this accessibility. In some school districts, it will take many years for 1:1 Technology to be present in all classrooms.

\section{The Benefits and Requirements of a 1:1 Educational Technology Initiative}

As 1:1 Technology is a rather new phenomenon in the educational world, it needs to be introduced carefully and with consideration. Technology, being laptops or devices, should be seen as tools and 
not replacements of best practices for teaching in the classroom. Another important component of 1:1 Technology is student motivation. The teacher in the classroom must understand how and why students are motivated to learn. In her study, Spears (2012) cites the work of Keller. Spears (2012, p. 8) cites the work of Keller (1987) and explains, "Attention, relevance, confidence, and satisfaction (ARCS) are the four characteristics one needs to establish in order for people to be motivated to learn." When looking to implement 1:1 Technology into a classroom, educators must look closely at their student population to understand who they are working with, how their students will learn best, and how to build their confidence with technology so they will, in return, be satisfied with their learning experience, and thus become motivated to learn. Educators cannot simply use technology as a replacement. Sansone et al. (2011) addresses motivation and note that students who already have a greater interest in computers may display greater knowledge and interest because the tasks they may do on a computer are already relevant to their interests and they are able to make connections on their own. This finding from Sansone et al. (2011) shows the importance of using the four characteristics from Keller (1987). Attention, relevance, confidence, and satisfaction all come into play with educators and students for technology to be introduced and used effectively in the classroom. In another study of 1:1 technology implementation in Texas, Shapley et al. (2011, p. 299) noted, "technology immersion had a positive effect on students' technology proficiency and frequency of their technology-based class activities and small-group interactions." With more and more emphasis being placed on student learning and achievement, schools are looking at making changes and immersing students and teachers with technology. With that, though, comes the ability and responsibility to train and uphold high standards of learning with both teachers and students.

Mark Edwards, a superintendent in Mooresville, North Carolina, has successfully launched 1:1 laptop initiatives in two school districts as acting superintendent. In this article, Edwards (2012) explains the excitement and energy factor that students have when learning due to 1:1 Technology being implemented. Edwards continues and explains in Mooresville the school district has created a very hands-on approach and exploratory way of learning with their technology. Edwards describes how teachers feel that even though the technology is in place and they are seeing academic gains in the classroom, most of these teachers would say that teaching is not easier. If anything, implementing 1:1 technology has made teaching more difficult and complex. Teaching with 1:1 technology "requires significant changes for individuals and teams with an exception for everyone to be committed to growth and improvement. Success in the classroom depends more than ever on the talent, initiative, and skills of the teacher" (Edwards, 2012, p. 6). Teaching is much more of a hands-on approach with 1:1 technology. Edwards calls this kind of teacher a "roaming conductor." This kind of teacher will move about the classroom engaging the students by posing questions and engaging students as needed.

One of the key elements in the instructional designs for this 1:1 laptop initiative in North Carolina is professional development. Edwards (2012, p. 8) states, "professional development is vital to successful teaching." He continues to explain that student success is connected to professional growth in teachers. 1:1 technology initiatives are not an isolated event with just one teacher; these kinds of technology initiatives take a building and culture of wanting to grow and change for the betterment of the students that are taught. As expectations are raised, teachers have been thoughtful and have used praxis to reflect upon the decisions they are making in the classroom when it comes to learning and achievement. According to Cavanaugh, Dawson and Ritzhaupt (2011) they state when a learning environment is comprised and changed with 1:1 technology that also, in turn, 
will change the teaching practices that are used in those classrooms. Cavanaugh et al. (2011, p. 360) cite the work of Barrios (2004) and note "the primary motivation for laptop classroom technology and accompanying teacher professional development is the belief that the new learning environment will support engaged students an increases in academic achievement." Without professional development for teachers, these academic gains and increases would be nearly impossible. The Florida Department of Education funded program, Leveraging Laptops: Effective Models for Enhancing Student Academic Achievement, professional development was a main component of this program for educators. Each teacher involved with this technology initiative was required to a four-day institute that focused on "student-centered, tool-based technology integration" (Cavanaugh et al., 2011, p. 360). In some districts that participated in this study, there were continual professional development opportunities online, and even some with small learning communities, coaching and modeling, technology trainers, and customary consulting. In order for technology immersion programs to be successful and obtain the outcomes that are desired, increased learning opportunities and higher academic achievement, these steps that the Florida Department of Education put in place to assist teachers with learning opportunities and growth is essential.

In order for any 1:1 technology initiative to become successful, funding must first be present. If there is no money to fund these initiatives and then fund the increased costs of manpower, infrastructure, and professional development, these initiatives will be ineffective and it will be difficult to obtain the desired results. As Race to the Top and the Common Core State Standards take effect, school districts across the state of Illinois and other states are looking for ways to increase student academic achievement and also prepare students for the demands of college and careers they may hold in the future. Technology is a tool that students and adults may use frequently outside of the classroom, but bringing technology into the classroom can allow students and teachers to learn in ways they never have before, thus changing the role of the teacher, the learner, and the environment in which learning takes place.

\section{Research Questions}

1) Does 1:1 Technology effect student academic achievement?

2) Does 1:1 Technology effect student motivation?

\section{Definition of Terms}

1:1 Technology- In education, this refers to the technological movement of every child in the classroom, school, school district, etc., having a laptop, or device, in the classroom to manipulate and learn with as a tool.

\section{Methods}

This quantitative research study looked at the mean scores of Topic Tests in the enVision Math series, Discovery Education Assessments, and attendance records to determine whether 1:1 
Technology was responsible for student academic achievement and motivation. The participants in this study are Fourth Grade students who attend school in Central Illinois. 1:1 Technology is a recent phenomenon in school districts across the country. As our world becomes more enriched with technology, school officials and administrators are looking for the positive impacts that technology can offer teachers and students, alike, in the classroom through meaningful and engaging teaching methods and instruction.

\section{Participants}

The participants in this quantitative study were Fourth Grade students from two different classrooms, but in the same Title 1 School, located in Central Illinois. According to the Illinois Interactive Report Card (2013), the school has a low-income rate of $84.3 \%$, with $40.5 \%$ of the students being African-American, 15.2\% Multiracial, 32.3\% Caucasian, 10.2\% Hispanic, 1.0\% American-Indian, and 0.7\% Asian.

This study examined how 1:1 Technology affects participants' academic achievement and motivation in the classroom. The study focused particularly on the Discovery Education Assessment, which is given four times a year, and also end of Topic Tests in Math to see if there are any significant differences in student scoring.

To gauge the motivational aspect of this research, monthly attendance records for each class were used. The school participating in this study splits the school day in half into Periods 1 and 2 . The number of absences was determined by adding the number of absences from Periods 1 and 2 for each classroom.

\section{Instrumentation}

In this study, Topic Tests in Math, Discovery Education Assessment (Math) results, and attendance were used to determine whether 1:1 Technology positively impacts student academic achievement and motivation in students. The Topic Tests were derived from the Pearson enVision Math series that has been adopted by the Bloomington Public School District 87. This specific Math series is Common Core State Standard aligned and teaches the language and lessons to meet these learning standards. The Topic Tests are used as summative assessments to gauge the mastery of Math skills.

The Discovery Education Assessment is an assessment that is administered via computer four times per school year. According to the Discovery Education Assessment Research, this assessment is used as a predictive benchmark assessment that provides data using state's curriculum standards and subskills for each item on the test. The Discovery Education Assessment can be used to improve instruction, help strengthen students' academic skills, and increase proficiency, as measured under No Child Left Behind and Race to the Top. These four assessments are administered throughout the school year with 9-12 weeks between each assessment. The predictive benchmark assessments are intended to predict performance on the next high-stakes test the student will take during the school year. 
Discovery Education Assessment uses a vertical scale score with scores ranging from 1000-2000. Discovery Education uses the Rasch Model of Item Response Theory (IRT), a single parameter model, to calculate the vertical scale. Attendance records were also analyzed to determine if there are any patterns of students being at school due to their motivation to learn with 1:1 Technology.

\section{Results}

The purpose of this study was to determine whether 1:1 Technology effects student academic achievement and motivation. 1:1 Technology refers to the technological movement of every child in the classroom, school, school district, etc., having a laptop in the classroom to manipulate and learn with as a tool. In the 1:1 Implementation classroom, 25 students participated in the study, whereas in the traditional classroom, only 22 students participated. The discrepancies between the numbers of students participating could skew or misrepresent the data that is gathered and analyzed for this study. The data gathered was then put into tables and figures to determine if 1:1 Implementation does truly effect student academic achievement and motivation. The motivational aspect for this study was measured using the student attendance records. The school that participated in this study splits the whole school day into Periods 1 and 2.

\section{Research Question 1: Does 1:1 Technology Affect Student Academic Achievement?}

In Table 1, there were some noticeable discrepancies in the Topic Test scores between the 1:1 Implementation Classroom and the Traditional Classroom. In Topic Tests 1 and 3, these mean scores were well above the Traditional Classroom, whereas in Topic Tests 5 and 6, the Traditional Classroom scored well above the 1:1 Implementation Classroom.

Table 1. Comparison of Topic Tests Scores between 1:1 Implementation Classroom and the Traditional Classroom

\begin{tabular}{lll}
\hline Name of Test & $1: 1$ Implementation Classroom & Traditional Classroom \\
\hline Topic Test 1 & $78.26 \%$ & $68.16 \%$ \\
\hline Topic Test 3 & $82.58 \%$ & $65.87 \%$ \\
\hline Topic Test 4 & $72.35 \%$ & $70.67 \%$ \\
\hline Topic Test 5 & $67.05 \%$ & $78.81 \%$ \\
\hline Topic Test 6 & $71.53 \%$ & $82.24 \%$ \\
\hline Topic Test 7 & $71.30 \%$ & $73.95 \%$ \\
\hline
\end{tabular}




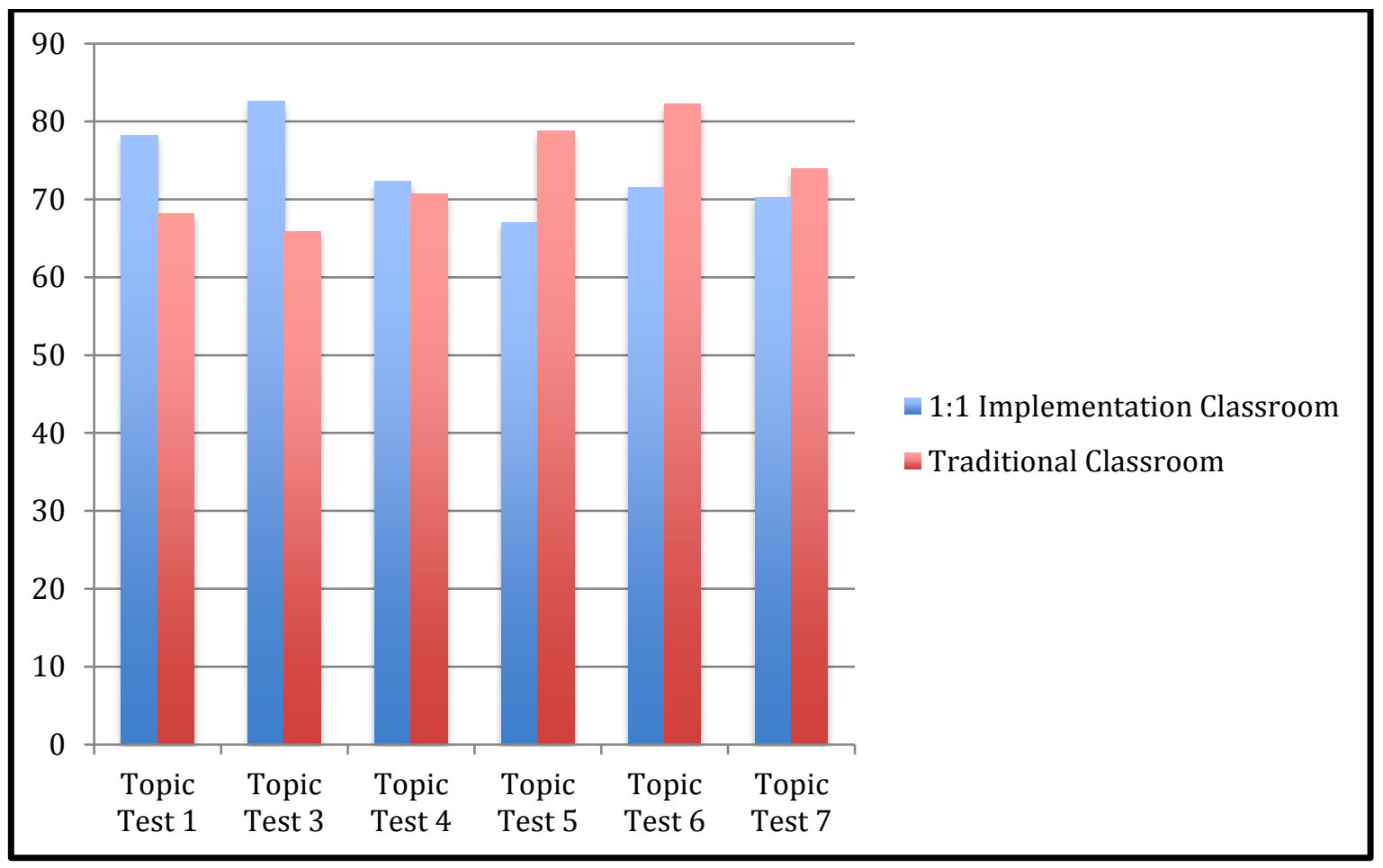

Figure 1. Comparison of Topic Tests Scores between 1:1 Implementation Classroom and the Traditional Classroom

\section{Research Question 2: Does 1:1 Technology Affect Student Motivation?}

In Table 2, students from the 1:1 Implementation Classroom scored higher on Discovery Assessment A than the Traditional Classroom, but in Discovery Assessment C, the students from the Traditional Classroom scored higher than the 1:1 Implementation Classroom.

Table 2- Comparison of Discovery Assessment scores between the 1:1 Implementation Classroom and the Traditional Classroom

\begin{tabular}{lll}
\hline Name of Test & $\mathbf{1 : 1}$ Implementation Classroom & Traditional Classroom \\
\hline Discovery Assessment A & 1436.68 & 1418.71 \\
\hline Discovery Assessment B & 1442.52 & 1437.86 \\
\hline Discovery Assessment C & 1495.35 & 1506.33 \\
\hline
\end{tabular}




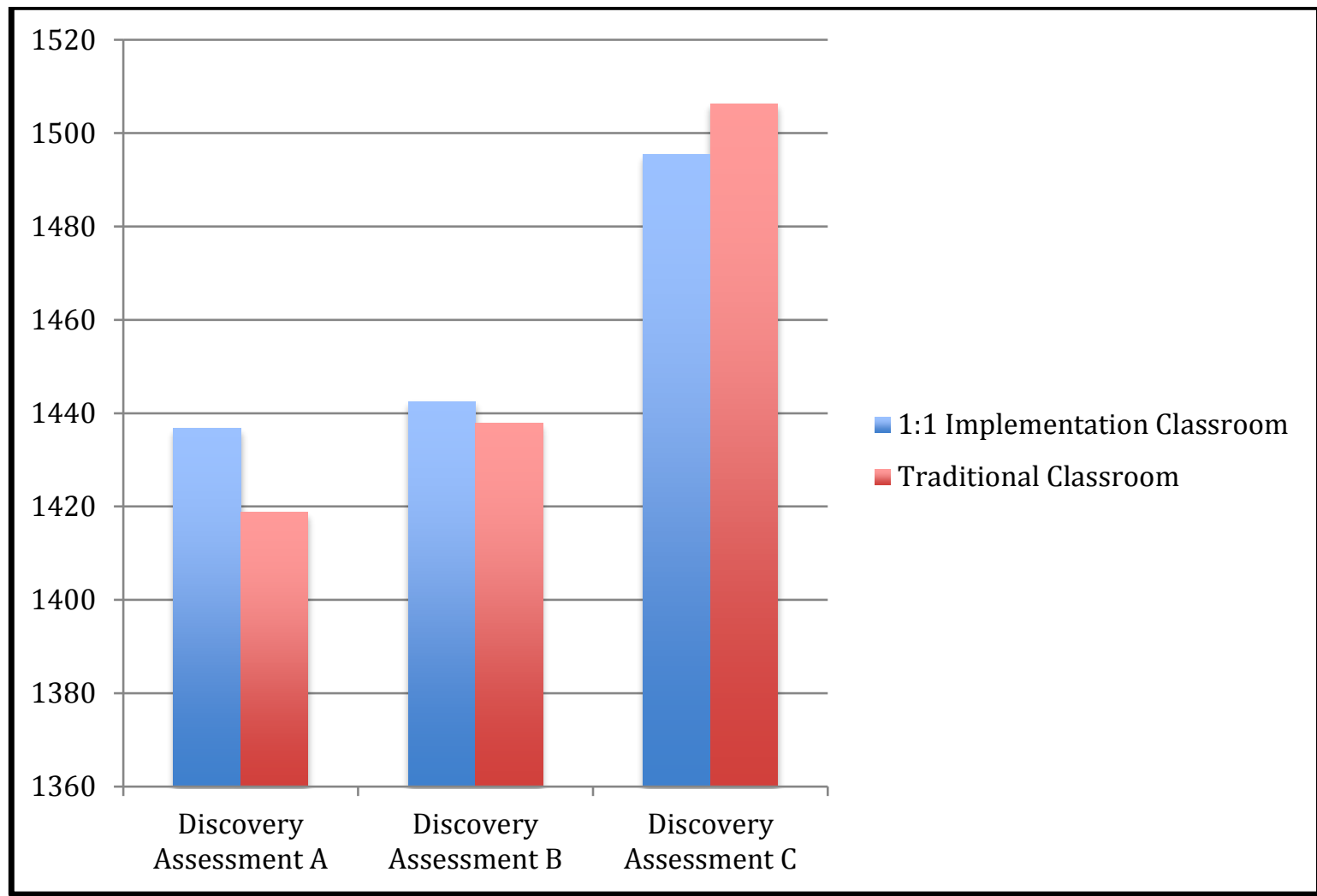

Figure 2. Comparison of Discovery Assessment scores between the 1:1 Implementation Classroom and the Traditional Classroom

In Table 3, the 1:1 Implementation Classroom had about the same attendance in October and November, but in December and January, the 1:1 Implementation Classroom had fewer absences than the Traditional Classroom.

Table 3- Comparison of Number of Absences between the 1:1 Implementation Classroom and the Traditional Classroom

\begin{tabular}{llllllll}
\hline & August & September & October & November & December & January & February \\
\hline $\begin{array}{l}\text { 1:1 } \\
\begin{array}{l}\text { Implementation } \\
\text { Classroom }\end{array}\end{array}$ & 16 & 37 & 27 & 33 & 36 & 52 & 54 \\
\hline $\begin{array}{l}\text { Traditional } \\
\text { Classroom }\end{array}$ & 4 & 23 & 24 & 34 & 42 & 60 & 32 \\
\hline
\end{tabular}




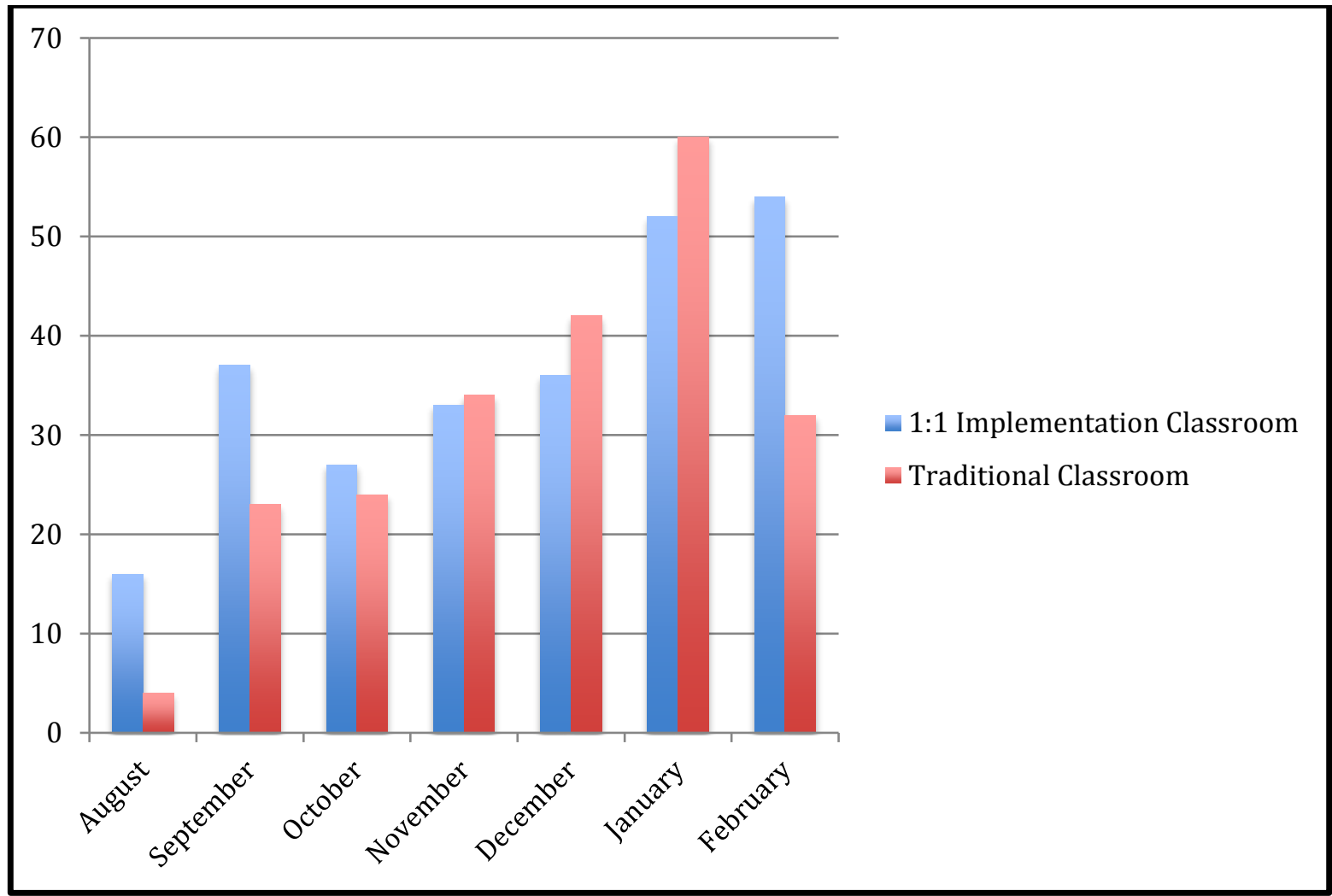

Figure 3. Comparison of Attendance Records between the 1:1 Implementation Classroom and the Traditional Classroom

\section{Discussion, Recommendation, and Conclusions}

As noted in the Results section of this study, 1:1 Implementation refers to the technological movement of every child in the classroom, school, school district, etc., having a laptop, or device, in the classroom to manipulate and learn with as a tool. The 1:1 Implementation Classroom was in its first year of implementation for the educator and also for the students participating in this study. This specific Fourth Grade classroom is one of two Fourth Grade classrooms used for Bloomington Public School District 87's technology pilot program.

\section{Research Question 1: Does 1:1 Technology Affect Student Academic Achievement?}

In regards to the results from Table 1 and Figure 1, Topic 3 Test was the first test administered by both classrooms at the beginning of the school year. The 1:1 Implementation Classroom scored significantly higher, $82.58 \%$ vs. $65.87 \%$, on this Topic Test than the Traditional Classroom. These scores could be a result from the newness of the laptops, the excitement of the students participating, and the ability to better differentiate using a laptop. In his article, Edwards (2012) mentions that excitement and energy factor that students elicited in his school district from students who had 1:1 Technology. Students in that school district were even inclined to miss recess 
to work on their projects and material in the classroom. In that same aspect, Topic 1 Test was the third test given of the school year and again, the 1:1 Implementation Classroom scored higher, $78.26 \%$ vs. $68.16 \%$, than the Traditional Classroom.

The Discovery Education Assessments $A$ and $B$ also yielded similar results. The 1:1 Implementation Classroom scored higher on tests $A$ and $B$ than did the Traditional Classroom. On Test $A$, the 1:1 Implementation Classroom measured a scale score of 1436.63, whereas the Traditional Classroom measured a scale score of 1418.71 . On Test B, the $1: 1 \mathrm{Implementation} \mathrm{Classroom} \mathrm{measured} \mathrm{a} \mathrm{scale}$ score of 1442.52 and the Traditional Classroom measured a scale score of 1437.86 . With the Discovery Education licensure Bloomington Public School District 87 has, Discovery Education allows educators to differentiate their instruction by analyzing the students' data on these assessments and creating probes to target students' strengths and weaknesses in the content area of Math. The 1:1 Implementation Classroom used these probes and they were assigned via the student dashboard on Discovery Education. Thus, the students in the 1:1 Implementation Classroom were able to tackle and solve problems that are worded and very similar to those questions that are present on the assessments. However, on Discovery Assessment $\mathrm{C}$, the Traditional Classroom scored around 10 points higher than the 1:1 Implementation Classroom. This could be a result from the Traditional Classroom being further in the Math curriculum for the school year than the 1:1 Implementation Classroom.

\section{Research Question 2: Does 1:1 Technology Affect Student Motivation?}

The attendance records were not what were expected for this study. The hypothesis for this study was to determine if 1:1 Technology would affect student academic achievement and motivation. The data from this study showed that the technology was not a particular factor in students being in attendance at school. However, this study was also done with Fourth Grade participants who are 9 and 10 years old. At this age, students have less autonomy than they do at the junior high or even high school level and rely more on their parents for guidance and support in their schooling efforts. In her study, Spears (2012, p. 8) cites the work of Keller (1987), stating attention, relevance, confidence, and satisfaction are all important components for students when technology is being introduced effectively in the classroom. For students to have the desire to be at school and learn, teachers must keep in mind best practices for teaching, but also keep in mind what is best for students and what is going to "hook" them to take learning to the next level. Also, not every child in the Traditional Classroom participated in this study, whereas in the 1:1 Implementation Classroom, all students participated. The discrepancies between the numbers of students participating could skew or misrepresent the data that is gathered and analyzed for this study, which could then skew or misrepresent the results.

Based on the literature used and the results gathered from this study, 1:1 Technology is a phenomenon that is being considered and adopted at high rates by school districts across the state and the nation to help students achieve at higher levels. For 1:1 Technology to be used correctly, school districts must look at two major components when it comes to student learning and instruction by the teacher in the classroom. Students must have exposure to technology to learn that a device is used for learning purposes. For 1:1 Technology to be implemented correctly from 
an educator standpoint, professional development and teamwork must be on going before, during, and after the implementation to help hone their newly acquired teaching skills.

While 1:1 Technology is being adopted at a rapid pace across the state and country, one must keep in mind that the device that is used in the classroom for student learning cannot simply be a replacement of best practices in teaching and learning for students. Teaching does not simply become easier due to the technology that is in place in the classroom. In this study, technology was not a sole factor in higher Topic Test scores, Discovery Education Assessment results, and student attendance records. There are some instances that technology appeared to have been an influence for higher scores, specifically in Discovery Assessments A and B, but overall, the data does not support the hypothesis that technology would increase student academic achievement and motivation. Teachers must continue to be learners themselves to produce the best teaching methods and introduce technology that works for their classroom and the specific needs of their students. What teachers decide to bring into the classroom, must "hook" students and make them excited to learn, thus, the programs, materials, and projects done should be meaningful to the students. When this is done correctly, school districts will see the product of higher engagement levels, higher achieving students, and the desire to be at school to learn.

\section{References}

Amelink, C., Scales, G., \& Tront, J. (2012). Student use of the Tablet PC: Impact on student learning behaviors. Advances in Engineering Education, 3(1), 1-17.

Barrios, T. (2004). Laptops for learning: final report and recommendations of the laptops for learning task force. Retrieved on 18 October 2007 from http://etc.usf.edu/L4L/

Brinkerhoff, J. (2006). Effects of a long-duration, professional development academy on technology skills, computer self-efficacy, and technology integration beliefs and practices. International Society for Technology in Education, 39(1), 22-43.

Cavanaugh, C., Dawson, K., \& Ritzhaupt, A. (2011). An evaluation of the conditions, processes, and consequences of laptop computing in K-12 classrooms. Journal of Educational Computing Research, 45(3), 359-378.

Donovan, L., Hartley, K., \& Strudler, N. (2007). Teacher concerns during initial implementation of a one-to-one laptop initiative at the middle school level. Journal of Research on Technology in Education, 39(3), 263-286.

Duncan, A. (2009, July 24). Education reform's moon shot. The Washington Post. Retrieved on 22 February 2016 from http://www.washingtonpost.com

Edwards, M. (2012). Our digital conversion. Education Digest, 78(1), 4-9.

Goals 2000: Educate America Act, H.R. 1804. (1994). Retrieved on 22 February 2016 from http://www2ed.gov.legislation/GOALS2000/TheAct/index.html

Illinois Interactive Report Card. (2013). Retrieved on 22 February 2016 from http://iirc.niu.edu/ School.aspx?schoolid=170640870252011 
Johnson, D. \& Maddux, C. (2003). Technology in education: A twenty-year retrospective. Computers in the Schools, 20(1/2), 1-186.

Keller, J. (1987). Strategies for stimulating the motivation to learn. Performance \& Instruction, 26(8), 1-7.

No Child Left Behind Act of 2001, P.L. 107-110. (2002). Retrieved on 22 February 2016 from http://www2ed.gov/policy/elsec/leg/esea02/index.html

President's Council of Advisors on Science and Technology. (2010). Report to the president. Prepare and inspire: K-12 education in science, technology, engineering, and math (STEM) for America's future. Retrieved on 22 February 2016 from http://www.whitehouse.gov/ sites/default/files/microsites/ostp/pcast-stemed-report.pdf

Race to the Top Program Executive Summary. (2009). Retrieved on 22 February 2016 from http://www2ed.gov/programs/racetothetop/executive-summary.pdf

Sansone, C., Fraughton, T., Zachary, J.L., Butner, J., \& Heiner C. (2011). Self-regulation of motivation when learning online: The importance of who, why, and how. Educational Technology Research \& Development, 59(2), 199-212.

Shapley, K., Sheehan, D., Maloney, C., \& Caranikas-Walker, F. (2011). Effects of technology immersion of middle school students' learning opportunities and achievement. Journal of Educational Research, 104(5), 299-315.

Spears, S. A. (2012). Technology-enhanced learning: The effects of 1:1 technology on student performance and motivation (Doctoral thesis). University of West Florida.

United States Department of Education. (2002). No Child Left Behind Act. Retrieved on 22 February 2016 from http://www2.ed.gov/policy/elsec/leg/esea02/index.html

Correspondence: Adel Al-Bataineh, Professor, School of Teaching and Learning, Illinois State University, Normal, Illinois, United States of America 